\title{
Functions of CD169 positive macrophages in human diseases (Review)
}

\author{
YU LIU ${ }^{1}$, YUAN XIA ${ }^{2}$ and CHUN-HONG QIU ${ }^{1}$ \\ ${ }^{1}$ Department of Cell Biology, School of Basic Medical Science, Cheeloo College of Medicine, Shandong University; \\ ${ }^{2}$ Department of Hematology, Qilu Hospital of Shandong University, Jinan, Shandong 250012, P.R. China
}

Received August 6, 2020; Accepted November 26, 2020

DOI: $10.3892 /$ br.2020.1402

\begin{abstract}
CD} 169^{+}$macrophages are a unique type of macrophage subset that differ from M1 and M2 macrophages. $\mathrm{CD}_{169^{+}}$macrophages are present in multiple tissues and organs throughout the body and are primarily expressed in secondary lymphoid organs. These cells are primarily divided across three locations in secondary lymphoid organs: The metallophilic marginal zone of the spleen, the subcapsular sinus and the medulla of the lymph nodes. Due to their unique location distribution in vivo and the presence of the CD169 molecule on their surfaces, $\mathrm{CD} 169^{+}$macrophages are reported to serve important roles in several processes, such as phagocytosis, antigen presentation, immune tolerance, viral infection and inflammatory responses. At the same time, it has been reported that $\mathrm{CD} 169^{+}$macrophages may also serve an important role in anti-tumour immunity. The present review focuses on the research progress surrounding the function of CD169+ macrophages in a variety of diseases, such as viral infection, autoimmune diseases and tumours.
\end{abstract}

\section{Contents}

\section{Introduction}

2. Biological function of the CD169 molecule

3. Development and phenotype of $\mathrm{CD} 169^{+}$macrophages

4. Roles of $\mathrm{CD}_{169} 9^{+}$macrophages in bone marrow

5. Role of $\mathrm{CD} 169^{+}$macrophages in antigen presentation

6. Functions of $\mathrm{CD} 169^{+}$macrophages in immune tolerance

7. Roles of $\mathrm{CD} 169^{+}$macrophages in autoimmune diseases

8. Antiviral effects of $\mathrm{CD} 169^{+}$macrophages

9. Anti-tumour roles of $\mathrm{CD} 169^{+}$macrophages

10. Conclusion

Correspondence to: Dr Chun-Hong Qiu, Department of Cell Biology, School of Basic Medical Science, Cheeloo College of Medicine, Shandong University, 44 Wenhuaxi Road, Jinan, Shandong 250012, P.R. China

E-mail: qiuchun@sdu.edu.cn

Key words: $\mathrm{CD}_{169^{+}}$macrophages, secondary lymphoid organs, viral infection, autoimmune diseases, tumours

\section{Introduction}

Macrophages are distributed throughout the body in various tissues and organs and show a high degree of heterogeneity and diversity (1). Several specific markers expressed on macrophage surfaces have been used to identify different subsets, such as F4/80, CD68, SRA-1 and CD169 (2). CD169+ macrophages are a unique subset of macrophages distributed across multiple tissues and organs of the human body. The results in the NCBI database showed that the CD169 molecules were expressed in 27 different tissues of the human body, such as the spleen, lymph node, small intestine, liver, lung, heart, kidney, colon, bone marrow and placenta, with a particularly high expression in the placenta, spleen, lymph nodes, lungs and bone marrow. The expression of CD169 also changes in these organs when the organ becomes diseased (Fig. 1) (3). Studies on CD169 ${ }^{+}$macrophages show its unique roles in certain diseases. CD169 ${ }^{+}$macrophages exhibit a unique location distribution, primarily in the secondary lymphoid organs where the blood and lymph enter and leave, and express the unique CD169 molecule on their surface (2). Unlike M1 and M2 macrophages, CD169+ macrophages can interact directly with $\mathrm{T}$ cells, B cells and dendritic cells (DC) through CD169 molecules to participate in immune regulation (4).

The discovery of CD169+ macrophages can be traced back to 1986 , when Crocker found a macrophage in the centre of the bone marrow hematopoietic island in mice that expressed a nonphagocytic, sialic acid-dependent sheep erythrocyte receptor, which was later termed $\mathrm{Sn}$, sialic acid binding immunoglobulin-like agglutinin (Siglec)-1 or CD169 (5). Several studies have shown significant changes in the number of $\mathrm{CD} 169^{+}$macrophages in pathological tissues, lymph nodes and peripheral blood under conditions of disease, such as cancer and autoimmune diseases (6-8). This suggests that $\mathrm{CD}_{169}{ }^{+}$macrophages are involved in the regulation of multiple immune responses and can serve as a potential molecular marker for predicting disease progression.

In the past 30 years, $\mathrm{CD} 169^{+}$macrophages have been studied in various fields. However, to date, there are still several aspects of their biology to be explored, including their differentiation and development, signal transduction pathways and modes of activation. With the successful development of mice with CD169 gene deletion and its application in various 


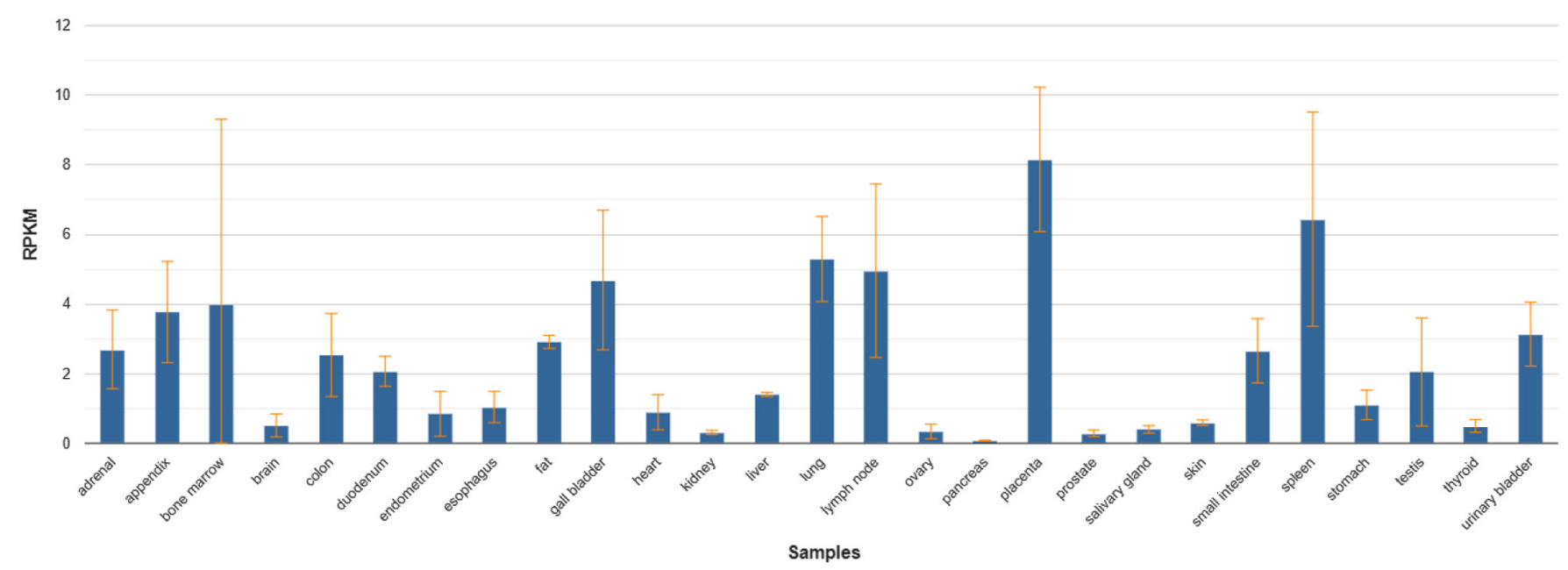

Figure 1. Expression of CD169 molecules in human tissues. RNA sequencing was performed on tissue samples from 95 human individuals representing 27 different tissues in order to determine tissue-specificity of the CD169 genes (3).

disease models, the roles of $\mathrm{CD} 169^{+}$macrophages in immune regulation are gradually being elucidated.

\section{Biological function of the CD169 molecule}

CD169, is a member of the Siglec family (9). It is primarily expressed on the surface of specific macrophage subsets and its precursor monocytes, as well as on some DCs or T lymphocytes (10). The CD169 molecule consists of 17 Ig-like domains, including an $\mathrm{N}$-terminal $\mathrm{V}$-set domain and $16 \mathrm{C} 2$-set domains, which are highly conserved in humans and mice (11). CD169 is involved in cell-to-cell adhesion and cell-pathogen interactions (12). The CD169 molecule endows CD169+ macrophages with their unique functions. Cells expressing CD169 have high affinity for $\alpha 2-3$-glycosyltransferase and glucosidase, and communicate with other immune cells by recognizing and binding other cell surface polysaccharides, such as CD43 on T cells (13). CD169 ${ }^{+}$macrophages in the marginal zone of the spleen recognize phosphatidylserine on the surface of apoptotic cells, present apoptotic cell antigens and recruit regulatory $\mathrm{T}$ cells (Tregs) to exhibit their role in immune tolerance (14). Furthermore, the recruitment of Tregs may negatively regulate the immune responses and inhibit autoimmune diseases (15-18). The CD169 molecule has been used as molecular marker in several autoimmune diseases to predict patient outcomes, such as Grave's diseases $(19,20)$. CD169 molecules in the marginal zone of the spleen are also key components participating in virus defence in the host, where it can bind to ganglioside GM3 on the surface of HIV-1 particles, capture viral particles and mediate viral infection (21). As an adhesion molecule, CD169 is a facilitator of the recognition and internalization of sialic acid decorated apoptotic bodies and exosomes derived from tumours. It can potentially contribute to both the attenuation as well as the facilitation of anti-tumour immunity (22). CD169 in lymph nodes, for example, are involved in immunomodulation with MUC-1 binding on the surface of breast cancer tumour cells (23). Moreover, CD169+ macrophages capture B cell-derived exosomes in the spleen and lymph nodes through their surface a2,3-linked sialic acids (24).

\section{Development and phenotype of $\mathrm{CD}^{169^{+}}$macrophages}

$\mathrm{CD} 69^{+}$macrophages are primarily reported to be present in three locations in the secondary lymphoid organs: The metallophilic marginal zone (MZM) of the spleen, the subcapsular sinus and the medulla of the lymph nodes (2). Mouse lymph node subcapsular sinus macrophages (SSMs) express

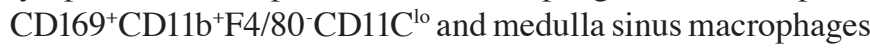
(MSMs) express $\mathrm{CD} 169^{+} \mathrm{F} 4 / 80^{+}$. These two groups of macrophages are derived from $\mathrm{CD}_{11} \mathrm{~b}^{+}$cell precursors in embryonic or adult mice and rely on lymph node mesenchymal and endothelial stromal cells to form a niche environment through the RANK-RANKL cytokine axis (25). MZM macrophages in the spleen express $\mathrm{CD} 169^{+} \mathrm{CD} 11 \mathrm{~b}^{+} \mathrm{F} 4 / 80^{-} \mathrm{CD} 11 \mathrm{C}^{\mathrm{lo}}$ and $\mathrm{CD} 169^{+}$ macrophages in the intestine are present far from the epithelial boundary, being primarily distributed in the colonic lamina propria, around the crypt, expressing $\mathrm{CD} 115^{+} \mathrm{CD} 169^{+} \mathrm{CD} 11 \mathrm{~b}^{+}$ $\mathrm{F} 4 / 80^{\text {lo }} \mathrm{CD}_{11 \mathrm{C}^{\mathrm{lo}}}(26)$. The surface markers of $\mathrm{CD} 169^{+}$macrophages in the colon lamina propria are similar to those in the spleen, but they differ widely with regard to differentiation. $\mathrm{CD}_{169^{+}}$macrophages express low levels of F4/80, indicating that they are not derived from yolk sac precursors (26). CD169+ macrophages in the colon lamina propria may originate partly from self-renewal of tissue resident macrophages and partly from blood stem cell supplementation (26).

Similar to most macrophages, the development of $\mathrm{CD} 169^{+}$ macrophages is regulated by CSF-1. CD169 expression was not detected in CSF-1 gene knockout mice, and injection of CSF-1 rescued the expression of CD169. In addition, interfering with the CSF-1 signalling pathway in the spleen of mice could quickly inhibit the generation of this cell $(27,28)$. The development of $\mathrm{CD} 169^{+}$macrophages also depends on lymphotoxin (LT)- $\alpha$ and LT $-\beta$ secreted by B cells, and the deletion of B cells or LT can affect cell development directly $(29,30)$. In the colon however, the development of $\mathrm{CD} 169^{+}$macrophages is dependent on vitamin A, rather than LT (26). Colonic CD169+ macrophages display different phenotypes, which is dependent on Maf expression levels in various phases of inflammation (31). Moreover, CD169 expression in the peripheral blood can be induced by type I interferon (IFN) in vitro, and both type I IFN levels and 
Table I. Macrophage populations in mouse secondary lymphoid organs and the colon.

\begin{tabular}{llll}
\hline Organ & \multicolumn{1}{c}{ Area } & Macrophage population & \\
\hline Spleen & Red pulp & Red pulp M $\Phi$ & Makers \\
& Marginal zone & MZM M $\Phi$ & F4/80, MR, CD68 \\
& & Outer MZ M $\Phi$ & CD169, CR-L, CD11b \\
& White pulp & White pulp M $\Phi$ & SR-A, Macro, SIGNR-1 \\
Lymph nodes & SS & SS M $\Phi$ & CD68, CR-L \\
& Medulla & Med M $\Phi$ & CD169, CR-L, CD11b \\
& Cortex & & CD169, SIGN-R1, Macro, SR-A, F4/80, MR \\
Colon & Lamina propria & Lamina propria & CD68 \\
& & CD169 ${ }^{+}$M $\Phi$ &
\end{tabular}

MФ, macrophages; SS, subcapsular sinus; R-L, ligand for the cysteine-rich domain of MR.

the expression of CD169 is increased in animal models and patients with autoimmune diseases (Table I) (32-36).

\section{Roles of $\mathrm{CD} 169^{+}$macrophages in bone marrow}

$\mathrm{CD}_{169}{ }^{+}$macrophages were initially found in the mouse bone marrow, located in the centre of the "erythroid hematopoietic island' $(5,37,38)$. This cell subset expresses several molecu les(CD169+VCAM-1 ${ }^{+}$ER-HR3 ${ }^{+}$CD11b ${ }^{+} \mathrm{F} 4 / 80^{+} \mathrm{Ly}^{-6 G^{+}}$) (39). $\mathrm{CD} 169^{+}$macrophages scavenge apoptotic cells and efflux nuclei produced during erythroid haematopoiesis by binding to sialose complexes on the surface of erythroid cells, maintaining the function and integrity of haematopoietic islands (40). Through the combination of CD169 and sialic acid complexes on the surface of erythroid cells, the apoptotic cells and the effluxed nuclei produced in erythroid haematopoiesis are eliminated (41). CD169+ macrophages also circulate iron in the blood, providing the nutritional microenvironment required for haematopoiesis (41). Postponed haematopoietic recovery was observed in a mice model of haemolytic anaemia induced by hydrazinobenzene, when monocyte clearance and CD $169^{+}$macrophage clearance were caused by disodium chloride phosphate liposomes (42). At the same time, CD169 ${ }^{+}$ macrophages promoted late erythrocyte maturation in the study of a mouse model of polycythaemia (43). These results suggested that $\mathrm{CD} 169^{+}$macrophages are essential in the development and maturation of erythrocytes and may provide a new avenue for the treatment of iron deficiency anaemia, erythrocyte regeneration disorder and polycythaemia (43). In studies of $\mathrm{CD}_{169^{+}}$macrophages in the bone marrow of mice, it was also found that the absence of $\mathrm{CD} 169^{+}$macrophages could lead to bone injury and inhibit bone repair, indicating that CD169+ macrophages may be helpful in maintaining bone homeostasis and bone regeneration (44). CD169 $9^{+}$macrophages also exist in the human bone marrow, and its distribution is similar to that in mice; however, the study of its roles in bone marrow are still limited, and their roles have not been fully elucidated.

\section{Role of $\mathrm{CD} 169^{+}$macrophages in antigen presentation}

In the lymph nodes and spleen, $\mathrm{CD} 169^{+}$macrophages are associated with the regions of organs exposed to body fluids, close to the $\mathrm{T}$ and $\mathrm{B}$ lymphocyte regions, which is consistent with their role in antigen processing (45). However, the effect of $\mathrm{CD} 169^{+}$macrophages in different parts of the body varies slightly. SSMs have poor endocytotic properties compared with MSMs, expressing only low levels of lysosomal enzymes with limited degradative ability (46). Thus, SSMs are not intended to degrade antigens but present these antigens to homologous or nonhomologous B cells along immunological synapses extending into the follicles. SSMs can even enter follicles under inflammatory conditions. The antigen recognition of $\mathrm{B}$ cells homologous to SSMs results in the activation of B cells and migration to T-B cell boundaries for assistance from Th cells (47). $\mathrm{CD} 169^{+}$macrophages present antigens to B cells via two means: $\mathrm{CD} 169^{+}$macrophages present antigens directly to homologous B cells or $\mathrm{CD} 169^{+}$macrophages acquire immune complexes that are delivered to follicular DCs in follicles to retain the native antigens, ensuring long-term presentation to B cells $(48,49)$. SSMs also secrete a large number of cytokines whilst presenting antigens, particularly type I IFN, increasing the cascade reaction produced by cytokines, leading to the influx of DCs, neutrophils and NK cells (50). MSMs are exposed to the medullary cords and flow out of the medullary cords of the lymph nodes before being excreted through the efferent lymphatic vessels. MSMs can phagocytose and present microbial antigens, but there is little evidence that they produce proinflammatory cytokines (2). Under certain conditions, $\mathrm{CD} 169^{+}$macrophages, particularly SSMs, cross-present to $\mathrm{CD}^{+} \mathrm{T}$ cells. The cross-presentation of $\mathrm{CD}^{+} \mathrm{T}$ cells by $\mathrm{CD}_{169}{ }^{+}$macrophages is performed via two methods: $\mathrm{CD} 169^{+}$ macrophages transfer antigens to the spleen $\mathrm{CD} \mathrm{a}^{+} \mathrm{DCs}$ and then to $\mathrm{CD}^{+} \mathrm{T}$ cells or $\mathrm{CD} 169^{+}$macrophages directly present antigens to $\mathrm{CD}^{+} \mathrm{T}$ cells $(13,51)$. In addition, $\mathrm{CD} 169^{+}$macrophages may also present lipid antigens to promote the activation of invariant natural killer T (iNKT) cells by expressing the MHC class of molecules, and iNKT cells further activate DC, NK, B and T cells by secreting cytokines (Table II) (52-54).

\section{Functions of $\mathrm{CD}^{169+}$ macrophages in immune tolerance}

Ravishankar et al (14) confirmed that $\mathrm{CD} 169^{+}$macrophages also participate in the immune tolerance induced by apoptotic cell clearance. Apoptotic cells are important sources of autoantigens; 
Table II. Development and functions of CD169+ macrophages.

\begin{tabular}{llll}
\hline Organ & Development & \multicolumn{1}{c}{ Area } & \multicolumn{1}{c}{ Functions } \\
\hline Lymph nodes & LT- $\alpha$ and LT- $\beta$ & SS & Low phagocytic, present antigens, secrete cytokines \\
Spleen & LT- $\alpha$ and LT- $\beta$ & Medulla & $\begin{array}{l}\text { Marginal zone } \\
\text { Engulf and present microbial antigens }\end{array}$ \\
Colon & Vitamin A & Lamina propria & $\begin{array}{l}\text { immune tolerance } \\
\text { Present antigens, secrete CCL8, recruit monocytes, promote inflammation }\end{array}$ \\
\hline
\end{tabular}

LT: lymphotoxin; SS: subcapsular sinus.

their normal clearance process may induce immune tolerance, and abnormal accumulation of autoantibodies can lead to the occurrence of autoimmune diseases (55-58). A previous report showed that $\mathrm{CD} 169^{+}$macrophages have a strong capacity to phagocytose apoptotic cells, by which immune homeostasis is maintained (59). Splenic CD169+ macrophages can bind to $\alpha 2,3$ - and $\alpha 2,6$-sialic acid on the surface of blood-derived apoptotic cells, thereby presenting apoptotic cell-associated antigens (60). Antigens are transmitted to CD8 $\mathrm{a}^{+} \mathrm{DCs}$ in the spleen and then activates $\mathrm{CD} 8^{+} \mathrm{T}$ cells in response to apoptotic cell-associated antigens $(61,62)$. CD169 ${ }^{+}$macrophages secrete CCL22 whilst presenting antigens and in-turn recruit Tregs through the CCL22-CCR4 axis, increasing the number of Tregs and inducing immune tolerance (63). However, injection of apoptotic cells into CD169-null mice resulted in an increase in autoantibodies, such as $\operatorname{IgG}$ and $\operatorname{IgM}$ and an increase in serum inflammatory factors (14). Nevertheless, the role of $\mathrm{CD} 169^{+}$macrophages in immune tolerance induced by other pathways remains unclear.

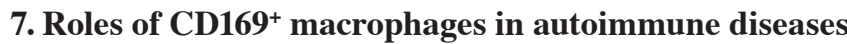

Macrophages usually maintain immune homeostasis by phagocytosis of foreign particles and production of anti-inflammatory factors, such as IL-10 (64). CD169+ macrophages do not exhibit changes in mice lacking MyD88-mediated Toll receptor signalling, and in mice in which bacterial flora have been eradicated, despite the high levels of bacterial flora in the colon and the importance of TLR signalling in mucosal homeostasis $(26,65)$. However, several studies have shown that activated $\mathrm{CD} 169^{+}$macrophages are involved in inflammatory responses during several autoimmune diseases. In the colon, $\mathrm{CD} 169^{+}$macrophages are reported to promote colitis progression in a dextran sulfate sodium (DSS)-induced IBD model $(66,67)$. The symptoms of colitis in DSS-induced mice were significantly alleviated in $\mathrm{CD} 169^{+}$macrophage-deficient CD169-DTR mice. Our previous study showed that the numbers of $\mathrm{CD} 169^{+}$macrophages in the mesenteric lymph nodes $(\mathrm{mLN})$ and abdominal cavity were higher in DSS-induced colitis mice than in the WT mice, with higher expression of mLN inflammatory cytokines, such as IL-17 and IL-6 (68). At the same time, the expression levels of the chemokine CCL22 decreased, together with decreased CCR4-expressing Treg cells, which are critical factors for maintaining homeostasis (63). A further study revealed that $\mathrm{CD} 169^{+}$macrophages respond to microbial antigens and produce CCL8 to recruit inflammatory monocytes that exacerbate inflammation during colitis (68). Moreover, the decrease in $\mathrm{CD} 169^{+}$macrophages in cyanidin 3-O-glucoside-treated colitis suggests that this subset could be a potential biomarker and therapeutic target (69).

Studies on human multiple sclerosis have shown that $\mathrm{CD}_{169}{ }^{+}$macrophages are abundantly present in MS patients, and have been used as selective markers for microglia and macrophages which are activated early in MS lesions (70). Treatment with CD169 neutralizing antibody in patients with rheumatoid arthritis significantly inhibited inflammation (71). The increased number of $\mathrm{CD} 169^{+}$macrophages in damaged tissues in a mouse experimental autoimmune encephalomyelitis (EAE) models and in human-derived IRBP peptide-induced experimental autoimmune uveoretinitis similarly inhibited Treg proliferation by binding sialic acid residues on the surface of Tregs (72). The depletion of CD169+ macrophages increases the numbers of Tregs and decreases the numbers of effector $\mathrm{T}$ (Teff) cells, and the severity of the disease is significantly reduced (72). In addition, $\mathrm{CD} 169^{+}$macrophages in the kidney regulate ICAM-1 expression and infiltration of inflammatory cells by interacting with endothelial cells (73).

\section{Antiviral effects of CD169+ macrophages}

In the past decade, the marginal zone of the mouse spleen has been shown to serve a very important role in host defence against pathogen infections, such as viruses $(74,75)$. $\mathrm{CD} 169^{+}$macrophages are reported to be the primary cell type infected during viral infection, and they can capture viral particles in the blood, absorb antigens, such as immune complexes and viruses, and then present them in a complete form to follicular B cells, inducing germinal centre B cellular responses $(30,76,77)$. CD169 ${ }^{+}$macrophages transfer antigens to $\mathrm{CD} 8 \mathrm{a}^{+} \mathrm{DCs}$ using the CD169 molecule, which preferentially participate in cell contact, eventually inducing an effective $\mathrm{CD}^{+} \mathrm{T}$ cell response (51). Moreover, CD169+ ${ }^{+}$macrophages have been shown to enforce viral replication, resulting in the delivery of a large number of viral antigens, and the amplification of T and B lymphocyte responses $(29,78)$. Type I IFN induced macrophages express CD169 molecules both in vivo and in vitro (50). $\mathrm{CD} 169^{+}$macrophages can also mediate antiviral activity by secreting type I IFN during viral infection. Since $\mathrm{CD} 169^{+}$macrophages simultaneously express programmed death ligands (PD-L1), the expression of IFN-I can upregulate the expression of PD-L1, which may result in $\mathrm{CD}^{+} \mathrm{T}$ cell exhaustion. The exhaustion of $\mathrm{CD}^{+} \mathrm{T}$ cells is 
a double-edged sword. In studies of lymphocytic choroidal meningitis virus infection in vivo, the persistent expression of IFN-I resulted in increased IL-10 and PD-L1 levels (79). IFN-I produced by $\mathrm{CD} 169^{+}$macrophages during chronic infection inhibits activation of the immune response to secondary infection (80). However, the absence of CD169+ macrophages results in inadequate production of IFN-I, reducing antiviral activity and persistence of the virus in the human body. Deletion of CD169+ macrophages also limits IFN-1 dependent PD-L1 expression. Without PD-L1, viral replication is enhanced, and the virus persists. At the same time, $\mathrm{CD}^{+} \mathrm{T}$ cell depletion is inhibited. Thus, in a mouse model, PD-L1 deletion resulted in the development of severe immunopathology and they died quickly following infection (79).

Similarly, mice infected with respiratory syncytial virus (RSV) also showed that the number of $\mathrm{CD} 69^{+}$macrophages localized in the alveoli increased significantly (81). CD169-diphtheria toxin receptor (DTR) mice revealed that the secretion of IFN- $\beta$, IL- 6 and TNF- $\alpha$ decreased when CD169 ${ }^{+}$ macrophages were absent, whereas $\mathrm{CD} 169^{+}$macrophage deletion reduced the aggregation of effector $\mathrm{CD} 8^{+} \mathrm{T}$ cells to the lungs following RSV mucosal infection. Overall, regulating the number of $\mathrm{CD}_{169^{+}}$macrophages to enhance the immune response to RSV infection may be a novel therapeutic strategy (82).

Some studies of retroviral HIV revealed that the expression of CD169 induced by IFN-I could promote cis-infection in bone marrow cells and target HIV to DC-mediated trans-infection pathways (82-86). Siglec-1 on the surface of CD169+ macrophages can recognize gangliosides in the lipid membrane of the virus, capture HIV particles, and further transmit the viral signal to DCs, leading to the infection of $\mathrm{CD}^{+} \mathrm{T}$ cells and reducing the antiviral effect of IFN-I $(87,88)$. Moreover, Siglec-1 induces the formation of a virus-containing compartment and enhances macrophage-to-T cell transmission of HIV-1 (83). Siglec-1 expression on pre-DCs amongst blood DCs promotes attachment and fusion of viral particles and mediates the replication-independent transfer of HIV-1 to activated primary T lymphocytes (20). Whether CD169+ macrophages serve an antiviral role or promote viral replication during viral infection is dependent on the genetic characteristics of the virus and the location of $\mathrm{CD} 169^{+}$macrophages. Altogether, the roles and mechanisms of $\mathrm{CD} 169^{+}$macrophages in humans infected with viruses still requires further study.

\section{Anti-tumour roles of $\mathrm{CD}_{169^{+}}$macrophages}

The production of cytotoxic T lymphocytes (CTLs) in tumour targeting CTLs is considered to be key in inducing antitumour immunity $(89,90)$. A previous study reported that CTLs and NK cells were activated by the subcutaneous injection of apoptotic tumour cells and they exhibited anti-tumour immunity effects (91). Antigen-presenting cells are critical for the activation of CTLs by capturing tumour cell-related antigens, which are primarily released from apoptotic tumour cells (92). $\mathrm{CD} 169^{+}$macrophages in lymph nodes and spleen were reported to present apoptotic tumour antigens. Additionally, intravenous injection of apoptotic tumour cells may be different from those obtained by subcutaneous injection of apoptotic tumour cells (93). Furthermore, tumour antigen-specific
$\mathrm{CD}^{+} \mathrm{T}$ cell activation and subsequent anti-tumour immune function in $\mathrm{CD} 169^{+}$macrophage-deficient mice was severely impaired $(13,59)$.

In human lymph nodes, $\mathrm{CD} 169^{+}$macrophages are primarily located in the paracortical area and in the medullary sinus, and express CD68 (6). Infiltration of these cells into local lymph nodes drains in patients with endometrial cancer, melanoma, colon cancer, bladder cancer, oesophageal cancer and diffuse large B cell lymphoma is associated with clinical staging, overall survival and clinical prognosis (94-99). A high density of $\mathrm{CD} 69^{+}$macrophages is indicative of a long survival period and a good clinical prognosis in patients with tumours. The density of $\mathrm{CD} 169^{+}$sinus macrophages correlates positively with $\mathrm{CD}^{+} \mathrm{T}$ cell or $\mathrm{CD}^{2} 7^{+} \mathrm{NK}$ cell infiltration in tumour tissues. The number of both $\mathrm{CD}^{+} \mathrm{T}$ cells and $\mathrm{CD} 57^{+} \mathrm{NK}$ cells in tumour nests and tumour stroma increased significantly when CD169+ regional lymph nodes (RLN) sinus macrophages were abundantly present (96). CD169+ ${ }^{+}$sinus macrophages exhibit direct contact with $\mathrm{CD}^{+} \mathrm{T}$ cells that express CD43, a major ligand of CD169, but whether interactions occur between CD169+ sinus macrophages and $\mathrm{CD} 57^{+} \mathrm{NK}$ cells in RLN has remained unclear (100). In a study of human head and neck squamous cell carcinoma, it was found that RLN metastasis was related to the density of CD169+ macrophages in the subcapsular sinus of the draining lymph nodes. The number of $\mathrm{CD} 169^{+}$macrophages in patients with lymphatic metastasis is lower than that in patients with lymphatic non-metastasis (101). These results suggest that the density of $\mathrm{CD} 169^{+}$macrophages may be used as a potential indicator for evaluating and detecting the clinical prognosis of malignant tumours.

In addition to $\mathrm{CD} 169^{+}$macrophages in lymph nodes, a large number of tumour-associated macrophages (TAMs) exist in the tumour microenvironment. TAMs are primarily composed of M2 type macrophages with immunosuppressive phenotypes. Regulation between different macrophages in the tumour microenvironment determines the progression of tumour development. For example, the predominant M2-polarized macrophages in bladder cancer can promote tumour angiogenesis and invasion, and they are associated with tumour grade (102). Two types of macrophage subsets, CD $204^{+}$macrophages and CD169+ macrophages, were labelled using specific labelling of different subsets of tumour-infiltrating macrophages (27). CD204, also known as scavenger receptor $\mathrm{A}$, is a phagocytic pattern recognition receptor that is primarily expressed in the medullary cells and is involved in the balance of functions, such as lipid metabolism and phagocytosis (103). It has been shown that the tumour microenvironment can upregulate the expression of CD204 on macrophages, whereas autocrine transforming growth factor $\beta$, which is produced by tumour-exposed macrophages, is involved in the downregulation of CD169 expression on these cells. In addition, a high density of tumour infiltrating $\mathrm{CD}_{204^{+}}$macrophages has been shown to be associated with a poor prognosis in patients with different types of cancer (104). Current clinical studies have found that the number of $\mathrm{CD} 169^{+}$macrophages in tumour-infiltrating macrophages in patients with liver cancer and urothelial cell carcinoma of the bladder is lower than that in the non-tumour tissues, but the opposite results have been observed in patients with gastric cancer (105). 


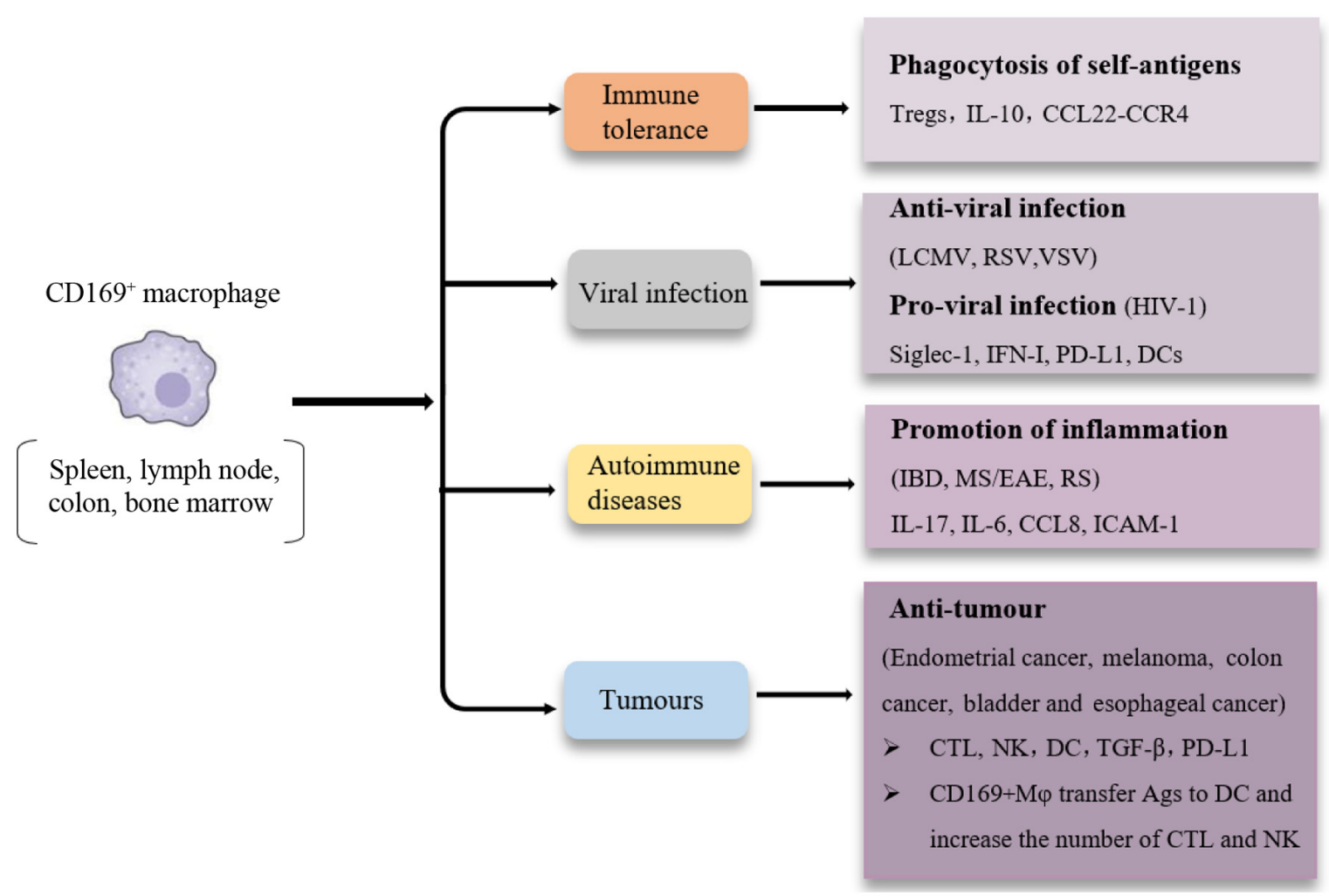

Figure 2. Summary of tissue $\mathrm{CD} 169^{+}$macrophages in various diseases. $\mathrm{CD} 169^{+}$macrophages in the spleen, lymph nodes, bone marrow and intestines have been reported in various biological processes and diseases, including immune tolerance, autoimmune diseases, virus infection and tumours.

\section{Conclusion}

$\mathrm{CD} 169^{+}$macrophages are widely distributed in vivo and have a variety of functions (Fig. 2). The role of $\mathrm{CD}_{169^{+}}$macrophages in immune regulation and several human diseases has been widely reported, and these cells can be used as an effective indicator to monitor disease progression and assess prognosis, and may also serve as novel targets for the treatment of several diseases. However, studies on CD169 ${ }^{+}$ macrophages in numerous diseases are not substantial enough to accurately determine their role and value, and identifying the signalling pathways and critical cytokines associated with $\mathrm{CD} 169^{+}$macrophages mediated pathways still need to be determined.

The developmental sources of $\mathrm{CD} 169^{+}$macrophages in different tissues and organs should also be determined. Self-renewal of tissue-resident $\mathrm{CD} 169^{+}$macrophages may have different functions to monocyte-derived $\mathrm{CD} 169^{+}$macrophages . To determine cell fate mapping of $\mathrm{CD} 169^{+}$macrophages and identify their developmental precursors in the intestine and other tissues and organs may assist in improving our understanding of the sources which allow for development of $\mathrm{CD} 169^{+}$macrophages. Moreover, $\mathrm{CD} 169^{+}$macrophages are different from M1 and M2 macrophages, as the CD169 ${ }^{+}$ can simultaneously express markers of M1/M2-type macrophages. $\mathrm{CD}_{169^{+}}$macrophages serve different roles in different tumours and this may be related to their location in tissues. PD-L1 expression on the surface of these $\mathrm{CD} 169^{+}$is upregulated during viral infections, but whether this also affects cell exhaustion and activation of tumour-infiltrating $\mathrm{CD}^{+} \mathrm{T}$ cells remains unknown. These cells in different microenvironments in different diseases may be regulated by different signals, thus polarizing these cells towards different states (106).

Although the roles of $\mathrm{CD} 169^{+}$macrophages in cancer studies have received more attention regarding their potential use as a therapeutic target, the current body of clinical and experimental studies have failed to provide suitable evidence of their application clinically. Contrary to previous studies, a recent article in mouse breast cancer suggested that CD169 ${ }^{+}$ macrophages in breast tumours inhibited the antitumour effects of $\mathrm{CD}^{+} \mathrm{T}$ cells by mediating the upregulation of PD-L1 expression via the JAK2 signalling pathways under the influence of tumour cells (107). Hence, further studies are required to reveal the complex roles and mechanisms of $\mathrm{CD} 169^{+}$macrophages in different tumour environments. Additional studies are required to identify effective methods for sorting $\mathrm{CD}_{169}{ }^{+}$macrophages for in vitro analysis and transcriptome sequencing of $\mathrm{CD} 169^{+}$macrophages to understand the signalling pathways and key cytokines involved in their regulation, and this may assist in improving our understanding of the mechanisms of $\mathrm{CD} 169^{+}$macrophages in different diseases.

\section{Acknowledgements}

Not applicable.

\section{Funding}

This work was supported by The Natural Science Foundation of Shandong Province (grant no. ZR2017MH003), and supported in part by the National Key Research and Development 
Program of China, the Ministry of Science and Technology (grant no. 2016YFE0127000).

\section{Availability of data and materials}

Not applicable.

\section{Authors' contributions}

YL, YX and CHQ wrote the manuscript. CHQ edited the manuscript. All authors read and approved the final manuscript.

\section{Ethics approval and consent to participate}

Not applicable.

\section{Patient consent for publication}

Not applicable.

\section{Competing interests}

The authors declare that they have no competing interests.

\section{References}

1. Varol C, Mildner A and Jung S: Macrophages: Development and tissue specialization. Annu Rev Immunol 33: 643-675, 2015.

2. Martinez-Pomares L and Gordon S: CD169+ macrophages at the crossroads of antigen presentation. Trends Immunol 33: 66-70, 2012.

3. Fagerberg L, Hallström BM, Oksvold P, Kampf C, Djureinovic D, Odeberg J, Habuka M, Tahmasebpoor S, Danielsson A, Edlund $\mathrm{K}$, et al: Analysis of the human tissue-specific expression by genome-wide integration of transcriptomics and antibody-based proteomics. Mol Cell Proteomics 13: 397-406, 2014.

4. Chávez-Galán L, Olleros ML, Vesin D and Garcia I: Much more than M1 and M2 macrophages, there are also CD169(+) and TCR(+) macrophages. Front Immunol 6: 263, 2015.

5. Li W, Wang Y, Zhao H, Zhang H, Xu Y, Wang S, Guo X, Huang Y, Zhang S, Han Y, et al: Identification and transcriptome analysis of erythroblastic island macrophages. Blood 134: 480-491, 2019.

6. Komohara Y, Ohnishi K and Takeya M: Possible functions of CD169-positive sinus macrophages in lymph nodes in anti-tumor immune responses. Cancer Sci 108: 290-295, 2017

7. Bao G, Han Z, Yan Z, Wang Q, Zhou Y, Yao D, Gu M, Chen B, Chen S, Deng A and Zhong R: Increased Siglec-1 expression in monocytes of patients with primary biliary cirrhosis. Immunol Invest 39: 645-660, 2010.

8. Strömvall K, Sundkvist K, Ljungberg B, Halin Bergström S and Bergh A: Reduced number of CD169(+) macrophages in pre-metastatic regional lymph nodes is associated with subsequent metastatic disease in an animal model and with poor outcome in prostate cancer patients. Prostate 77: 1468-1477, 2017.

9. Biesen R, Demir C, Barkhudarova F, Grün JR, Steinbrich-Zöllner M, Backhaus M, Häupl T, Rudwaleit M, Riemekasten G, Radbruch A, et al: Sialic acid-binding Ig-like lectin 1 expression in inflammatory and resident monocytes is a potential biomarker for monitoring disease activity and success of therapy in systemic lupus erythematosus. Arthritis Rheum 58: $1136-1145,2008$

10. Zhang J, Xu J, Zhang RX, Zhang Y, Ou QJ, Li JQ, Jiang ZZ, Wu XJ, Fang YJ and Zheng L: CD169 identifies an activated CD8(+) T cell subset in regional lymph nodes that predicts favorable prognosis in colorectal cancer patients. Oncoimmunology 5 : e1177690, 2016.

11. Nycholat CM, Rademacher C, Kawasaki N and Paulson JC: In silico-aided design of a glycan ligand of sialoadhesin for in vivo targeting of macrophages. J Am Chem Soc 134: 15696-15699, 2012.
12. Oetke C, Vinson MC, Jones $\mathrm{C}$ and Crocker PR Sialoadhesin-deficient mice exhibit subtle changes in B- and T-cell populations and reduced immunoglobulin M levels. Mol Cell Biol 26: 1549-1557, 2006.

13. Edgar LJ, Kawasaki N, Nycholat CM and Paulson JC: Targeted delivery of antigen to activated CD169(+) macrophages induces bias for expansion of CD8(+) T cells. Cell Chem Biol 26: 131-136. e4, 2019.

14. Ravishankar B, Shinde R, Liu H, Chaudhary K, Bradley J, Lemos HP, Chandler P, Tanaka M, Munn DH, Mellor AL and McGaha TL: Marginal zone CD169+ macrophages coordinate apoptotic cell-driven cellular recruitment and tolerance. Proc Natl Acad Sci USA 111: 4215-4220, 2014.

15. Panduro M, Benoist C and Mathis D: Tissue tregs. Annu Rev Immunol 34: 609-633, 2016.

16. Sakaguchi S, Yamaguchi T, Nomura T and Ono M: Regulatory T cells and immune tolerance. Cell 133: 775-787, 2008.

17. Sakaguchi S, Ono M, Setoguchi R, Yagi H, Hori S, Fehervari Z, Shimizu J, Takahashi T and Nomura T: Foxp3 ${ }^{+} \mathrm{CD} 25^{+} \mathrm{CD} 4^{+}$ natural regulatory $\mathrm{T}$ cells in dominant self-tolerance and autoimmune disease. Immunol Rev 212: 8-27, 2006.

18. Wu C, Rauch U, Korpos E, Song J, Loser K, Crocker PR and Sorokin LM: Sialoadhesin-positive macrophages bind regulatory $\mathrm{T}$ cells, negatively controlling their expansion and autoimmune disease progression. J Immunol 182: 6508-6516, 2009.

19. Ramos-Leví AM and Marazuela M: Pathogenesis of thyroid autoimmune disease: The role of cellular mechanisms. Endocrinol Nutr 63: 421-429, 2016.

20. Hashimoto K, Nishihara E, Matsumoto M, Matsumoto S, Nakajima Y, Tsujimoto K, Yamakage H, Satoh-Asahara N, Noh JY, Ito K, et al: Sialic acid-binding immunoglobulin-like lectin1 as a novel predictive biomarker for relapse in Graves disease: A multicenter study. Thyroid 28: 50-59, 2018.

21. Ruffin N, Gea-Mallorquí E, Brouiller F, Jouve M, Silvin A, See P, Dutertre CA, Ginhoux F and Benaroch P: Constitutive Siglec-1 expression confers susceptibility to HIV-1 infection of human dendritic cell precursors. Proc Natl Acad Sci USA 116: 21685-21693, 2019.

22. Fraschilla I and Pillai S: Viewing Siglecs through the lens of tumor immunology. Immunol Rev 276: 178-191, 2017.

23. Shiota T, Miyasato Y, Ohnishi K, Yamamoto-Ibusuki M, Yamamoto Y, Iwase H, Takeya M and Komohara Y: The clinical significance of CD169-positive lymph node macrophage in patients with breast cancer. PLoS One 11: e0166680, 2016.

24. Saunderson SC, Dunn AC, Crocker PR and McLellan AD CD169 mediates the capture of exosomes in spleen and lymph node. Blood 123: 208-216, 2014.

25. Camara A, Cordeiro OG, Alloush F, Sponsel J, Chypre M, Onder L, Asano K, Tanaka M, Yagita H, Ludewig B, et al: Lymph node mesenchymal and endothelial stromal cells cooperate via the RANK-RANKL cytokine axis to shape the sinusoidal macrophage niche. Immunity 50: 1467-1481, 2019.

26. Hiemstra IH, Beijer MR, Veninga H, Vrijland K, Borg EG, Olivier BJ, Mebius RE, Kraal G and den Haan JM: The identification and developmental requirements of colonic CD169+ macrophages. Immunology 142: 269-278, 2014.

27. Lescoat A, Ballerie A, Augagneur Y, Morzadec C, Vernhet L, Fardel O, Jégo P, Jouneau S and Lecureur V: Distinct properties of human M-CSF and GM-CSF monocyte-derived macrophages to simulate pathological lung conditions in vitro: Application to systemic and inflammatory disorders with pulmonary involvement. Int J Mol Sci 19: 894, 2018

28. Vance J, Santos A, Sadofsky L, Morice A and Cervantes J: Effect of high glucose on human alveolar macrophage phenotype and phagocytosis of mycobacteria. Lung 197: 89-94, 2019.

29. Friedrich SK, Lang PA, Friebus-Kardash J, Duhan V, Bezgovsek J and Lang KS: Mechanisms of lymphatic system-specific viral replication and its potential role in autoimmune disease. Clin Exp Immunol 195: 64-73, 2019.

30. Xu HC, Huang J, Khairnar V, Duhan V, Pandyra AA, Grusdat M, Shinde P, McIlwain DR, Maney SK, Gommerman J, et al: Deficiency of the B cell-activating factor receptor results in limited $\mathrm{CD} 169^{+}$macrophage function during viral infection. J Virol 89: 4748-4759, 2015.

31. Kikuchi K, Iida M,Ikeda N, Moriyama S, Hamada M, Takahashi S, Kitamura H, Watanabe T, Hasegawa Y,Hase K, et al: Macrophages switch their phenotype by regulating Maf expression during different phases of inflammation. J Immunol 201: 635-651, 2018.

32. Yao H, Zhang Y, Xie B, Shang Y, Yuan S and Zhang J: Sleep-restriction inhibits neurogenesis through decreasing the infiltration of CD169(+) macrophages to ischemic brain after stroke. Neuroscience 431: 222-236, 2020. 
33. Spaulding E, Fooksman D, Moore JM, Saidi A, Feintuch CM, Reizis B, Chorro L, Daily J and Lauvau G: STING-licensed macrophages prime type I IFN production by plasmacytoid dendritic cells in the bone marrow during severe plasmodium yoelii malaria. PLoS Pathog 12: e1005975, 2016.

34. Chavez M, Silvestrini MT, Ingham ES, Fite BZ, Mahakian LM, Tam SM, Ilovitsh A, Monjazeb AM, Murphy WJ, Hubbard NE, et al: Distinct immune signatures in directly treated and distant tumors result from TLR adjuvants and focal ablation. Theranostics 8: 3611-3628, 2018.

35. Ferreira RC, Guo H, Coulson RM, Smyth DJ, Pekalski ML, Burren OS, Cutler AJ, Doecke JD, Flint S, McKinney EF, et al: A type I interferon transcriptional signature precedes autoimmunity in children genetically at risk for type 1 diabetes. Diabetes 63: 2538-2550, 2014.

36. Rose T, Szelinski F, Lisney A, Reiter K, Fleischer SJ Burmester GR, Radbruch A, Hiepe F, Grützkau A, Biesen R and Dörner T: Siglecl is a biomarker of disease activity and indicates extraglandular manifestation in primary Sjögren's syndrome. RMD Open 2: e000292, 2016.

37. Seu KG, Papoin J, Fessler R, Hom J, Huang G, Mohandas N, Blanc L and Kalfa TA: Unraveling macrophage heterogeneity in erythroblastic islands. Front Immunol 8: 1140, 2017.

38. Falchi M, Varricchio L, Martelli F, Masiello F, Federici G, Zingariello M, Girelli G, Whitsett C, Petricoin EF III, Moestrup SK, et al: Dexamethasone targeted directly to macrophages induces macrophage niches that promote erythroid expansion. Haematologica 100: 178-187, 2015.

39. Jacobsen RN, Forristal CE, Raggatt LJ, Nowlan B, Barbier V, Kaur S, van Rooijen N, Winkler IG, Pettit AR and Levesque JP Mobilization with granulocyte colony-stimulating factor blocks medullar erythropoiesis by depleting F4/80(+)VCAM1(+) CD169(+)ER-HR3(+)Ly6G(+) erythroid island macrophages in the mouse. Exp Hematol 42: 547-561.e4, 2014.

40. Chow A, Huggins M, Ahmed J, Hashimoto D, Lucas D, Kunisaki Y, Pinho S, Leboeuf M, Noizat C, van Rooijen N, et al: $\mathrm{CD}_{169^{+}}$macrophages provide a niche promoting erythropoiesis under homeostasis and stress. Nat Med 19: 429-436, 2013.

41. Kaur S, Raggatt LJ, Millard SM, Wu AC, Batoon L, Jacobsen RN, Winkler IG, MacDonald KP, Perkins AC, Hume DA, et al: Self-repopulating recipient bone marrow resident macrophages promote long-term hematopoietic stem cell engraftment. Blood 132: 735-749, 2018

42. Gbotosho OT, Kapetanaki MG, Ross M, Ghosh S, Weidert F, Bullock GC, Watkins S, Ofori-Acquah SF and Kato GJ: Nrf2 deficiency in mice attenuates erythropoietic stress-related macrophage hypercellularity. Exp Hematol 84: 19-28.e4, 2020.

43. Zhang RR and Zhu XF: Relationship between macrophages and erythropoiesis. Zhongguo Dang Dai Er Ke Za Zhi 18: 94-99, 2016 (In Chinese)

44. Batoon L, Millard SM, Wullschleger ME, Preda C, Wu AC Kaur S, Tseng HW, Hume DA, Levesque JP, Raggatt LJ and Pettit AR: CD169(+) macrophages are critical for osteoblast maintenance and promote intramembranous and endochondral ossification during bone repair. Biomaterials 196: 51-66, 2019.

45. Asano K, Kikuchi K and Tanaka M: CD169 macrophages regulate immune responses toward particulate materials in the circulating fluid. J Biochem 164: 77-85, 2018.

46. De Schryver M, Leemans A, Pintelon I, Cappoen D, Maes L, Caljon G, Cos P and Delputte PL: Comparative analysis of the internalization of the macrophage receptor sialoadhesin in human and mouse primary macrophages and cell lines. Immunobiology 222: 797-806, 2017.

47. Louie DAP and Liao S: Lymph Node Subcapsular sinus macrophages as the frontline of lymphatic immune defense. Front Immunol 10: 347, 2019.

48. Heath WR, Kato Y, Steiner TM and Caminschi I: Antigen presentation by dendritic cells for B cell activation. Curr Opin Immunol 58: 44-52, 2019

49. Veninga $H$, Borg EG, Vreeman $K$, Taylor PR, Kalay $H$, van Kooyk Y, Kraal G, Martinez-Pomares L and den Haan JM: Antigen targeting reveals splenic $\mathrm{CD} 169^{+}$macrophages as promoters of germinal center B-cell responses. Eur J Immunol 45: 747-757, 2015.

50. Grabowska J, Lopez-Venegas MA, Affandi AJ and den Haan JMM: CD169+ macrophages capture and Dendritic cells instruct: The interplay of the gatekeeper and the general of the immune system. Front Immunol 9: 2472, 2018.

51. Van Dinther D, Veninga H, Iborra S, Borg EGF, Hoogterp L, Olesek K, Beijer MR, Schetters STT, Kalay H, Garcia-Vallejo JJ, et al: Functional CD169 on macrophages mediates interaction with Dendritic cells for CD8(+) T Cell cross-priming. Cell Rep 22: 1484-1495, 2018.
52. Barral P, Polzella P, Bruckbauer A, van Rooijen N, Besra GS, Cerundolo V and Batista FD: CD169(+) macrophages present lipid antigens to mediate early activation of iNKT cells in lymph nodes. Nat Immunol 11: 303-312, 2010.

53. Kawasaki N, Vela JL, Nycholat CM, Rademacher C, Khurana A, van Rooijen N, Crocker PR, Kronenberg M and Paulson JC: Targeted delivery of lipid antigen to macrophages via the CD169/sialoadhesin endocytic pathway induces robust invariant natural killer T cell activation. Proc Natl Acad Sci USA 110: 7826-7831, 2013

54. Covarrubias R, Wilhelm AJ and Major AS: Specific deletion of LDL receptor-related protein on macrophages has skewed in vivo effects on cytokine production by invariant natural killer T cells. PLoS One 9: e102236, 2014.

55. Trahtemberg U and Mevorach D: Apoptotic cells induced signaling for immune homeostasis in macrophages and Dendritic cells. Front Immunol 8: 1356, 2017.

56. Vives-Pi M, Rodríguez-Fernández S and Pujol-Autonell I: How apoptotic $\beta$-cells direct immune response to tolerance or to autoimmune diabetes: A review. Apoptosis 20: 263-272, 2015.

57. Tanaka M and Miyake Y: Apoptotic cell clearance and autoimmune disorder. Curr Med Chem 14: 2892-2897, 2007.

58. Miyake Y, Asano K, Kaise H, Uemura M, Nakayama M and Tanaka M: Critical role of macrophages in the marginal zone in the suppression of immune responses to apoptotic cell-associated antigens. J Clin Invest 117: 2268-2278, 2007.

59. Asano K, Nabeyama A, Miyake Y, Qiu CH, Kurita A, Tomura M, Kanagawa O, Fujii S and Tanaka M: CD169-positive macrophages dominate antitumor immunity by crosspresenting dead cell-associated antigens. Immunity 34: 85-95, 2011.

60. Ravishankar B, Liu H, Shinde R, Chandler P, Baban B, Tanaka M, Munn DH, Mellor AL, Karlsson MC and McGaha TL: Tolerance to apoptotic cells is regulated by indoleamine 2,3-dioxygenase. Proc Natl Acad Sci USA 109: 3909-3914, 2012.

61. Black LV,Saunderson SC, Coutinho FP,Muhsin-Sharafaldine MR, Damani TT, Dunn AC and McLellan AD: The CD169 sialoadhesin molecule mediates cytotoxic T-cell responses to tumour apoptotic vesicles. Immunol Cell Biol 94: 430-438, 2016.

62. Qiu CH, Miyake Y, Kaise H, Kitamura H, Ohara O and Tanaka M: Novel subset of CD8\{alpha\}+ dendritic cells localized in the marginal zone is responsible for tolerance to cell-associated antigens. J Immunol 182: 4127-4136, 2009.

63. Hao S, Han X, Wang D, Yang Y, Li Q, Li X and Qiu CH: Critical role of CCL22/CCR4 axis in the maintenance of immune homeostasis during apoptotic cell clearance by splenic CD8 $\alpha(+)$ CD103(+) dendritic cells. Immunology 148: 174-186, 2016.

64. Shapouri-Moghaddam A, Mohammadian S, Vazini H, Taghadosi M Esmaeili SA, Mardani F, Seifi B, Mohammadi A, Afshari JT and Sahebkar A: Macrophage plasticity, polarization, and function in health and disease. J Cell Physiol 233: 6425-6440, 2018.

65. Detienne S, Welsby I, Collignon C, Wouters S, Coccia M, Delhaye S, Van Maele L, Thomas S, Swertvaegher M, Detavernier A, et al: Central role of CD169(+) lymph node resident macrophages in the adjuvanticity of the QS-21 component of AS01. Sci Rep 6: 39475, 2016.

66. Wang D, Li Q, Yang Y, Hao S, Han X, Song J, Yin Y, Li X, Tanaka M and Qiu CH: Macrophage subset expressing CD169 in peritoneal cavity-regulated mucosal inflammation together with lower levels of CCL22. Inflammation 40: 1191-1203, 2017.

67. Li Q, Wang D, Hao S, Han X, Xia Y, Li X, Chen Y, Tanaka M and Qiu CH: CD169 expressing macrophage, a key subset in mesenteric lymph nodes promotes mucosal inflammation in dextran sulfate sodium-induced colitis. Front Immunol 8: 669, 2017.

68. Asano K, Takahashi N, Ushiki M, Monya M, Aihara F, Kuboki E, Moriyama S, Iida M, Kitamura H, Qiu CH, et al: Intestinal CD169(+) macrophages initiate mucosal inflammation by secreting CCL8 that recruits inflammatory monocytes. Nat Commun 6: 7802,2015

69. Xia Y, Tian LM, Liu Y, Guo KS, Lv M, Li QT, Hao SY, Ma CH, Chen YX, Tanaka M, et al: Low dose of cyanidin-3-O-glucoside alleviated dextran sulfate sodium-induced colitis, mediated by CD169+ macrophage pathway. Inflamm Bowel Dis 25: 1510-1521, 2019.

70. Bogie JF, Boelen E, Louagie E, Delputte P, Elewaut D, van Horssen J, Hendriks JJ and Hellings N: CD169 is a marker for highly pathogenic phagocytes in multiple sclerosis. Mult Scle 24: 290-300, 2018

71. Xiong YS, Cheng Y, Lin QS, Wu AL, Yu J, Li C, Sun Y, Zhong RQ and Wu LJ: Increased expression of Siglec-1 on peripheral blood monocytes and its role in mononuclear cell reactivity to autoantigen in rheumatoid arthritis. Rheumatology (Oxford) 53: $250-259,2014$ 
72. Guo X, Nakamura K, Kohyama K, Harada C, Behanna HA, Watterson DM, Matsumoto Y and Harada T: Inhibition of glial cell activation ameliorates the severity of experimental autoimmune encephalomyelitis. Neurosci Res 59: 457-466, 2007.

73. Karasawa K, Asano K, Moriyama S, Ushiki M, Monya M, Iida M, Kuboki E, Yagita H, Uchida K, Nitta K and Tanaka M: Vascular-resident CD169-positive monocytes and macrophages control neutrophil accumulation in the kidney with ischemia-reperfusion injury. J Am Soc Nephrol 26: 896-906, 2015.

74. Shinde PV, Xu HC, Maney SK, Kloetgen A, Namineni S, Zhuang Y, Honke N, Shaabani N, Bellora N, Doerrenberg M, et al: Tumor necrosis factor-mediated survival of CD169(+) cells promotes immune activation during vesicular stomatitis virus infection. J Virol 92: e01637-e01617, 2018.

75. Uchil PD, Pi R, Haugh KA, Ladinsky MS, Ventura JD, Barrett BS, Santiago ML, Bjorkman PJ, Kassiotis G, Sewald X and Mothes W: A protective role for the lectin CD169/Siglec-1 against a pathogenic murine retrovirus. Cell Host Microbe 25 87-100.e10, 2019.

76. Frederico B, Chao B, Lawler C, May JS and Stevenson PG: Subcapsular sinus macrophages limit acute gammaherpesvirus dissemination. J Gen Virol 96: 2314-2327, 2015.

77. Junt T, Moseman EA, Iannacone M, Massberg S, Lang PA, Boes M, Fink K, Henrickson SE, Shayakhmetov DM, Di Paolo NC, et al: Subcapsular sinus macrophages in lymph nodes clear lymph-borne viruses and present them to antiviral $\mathrm{B}$ cells. Nature 450: 110-114, 2007.

78. Honke N, Shaabani N, Merches K, Gassa A, Kraft A, Ehrhardt K, Häussinger D, Löhning M, Dittmer U, Hengel $\mathrm{H}$, et al: Immunoactivation induced by chronic viral infection inhibits viral replication and drives immunosuppression through sustained IFN-I responses. Eur J Immunol 46: 372-380, 2016.

79. Shaabani N, Duhan V, Khairnar V, Gassa A, Ferrer-Tur R, Häussinger D, Recher M, Zelinskyy G, Liu J, Dittmer U, et al: CD169(+) macrophages regulate PD-L1 expression via type I interferon and thereby prevent severe immunopathology after LCMV infection. Cell Death Dis 7: e2446, 2016.

80. Teijaro JR: Too much of a good thing: Sustained type 1 interferon signaling limits humoral responses to secondary viral infection. Eur J Immunol 46: 300-302, 2016.

81. Oh DS, Oh JE, Jung HE and Lee HK: Transient depletion of CD169(+) cells contributes to impaired early protection and effector CD8(+) T cell recruitment against mucosal respiratory syncytial virus infection. Front Immunol 8: 819, 2017.

82. Jans J, Unger WWJ, Vissers M, Ahout IML, Schreurs I, Wickenhagen A, de Groot R, de Jonge MI and Ferwerda G: Siglec-1 inhibits RSV-induced interferon gamma production by adult T cells in contrast to newborn T cells. Eur J Immunol 48: 621-631, 2018.

83. Hammonds JE, Beeman N, Ding L, Takushi S, Francis AC, Wang JJ, Melikyan GB and Spearman P: Siglec-1 initiates formation of the virus-containing compartment and enhances macrophage-to-T cell transmission of HIV-1. PLoS Pathog 13: e1006181, 2017.

84. Jobe O, Kim J and Rao M: The role of Siglec-1 in HIV-1/macrophage interaction. Macrophage (Houst) 3: e1435, 2016.

85. Pino M, Erkizia I, Benet S, Erikson E, Fernández-Figueras MT, Guerrero D, Dalmau J, Ouchi D, Rausell A, Ciuffi A, et al: HIV-1 immune activation induces Siglec-1 expression and enhances viral trans-infection in blood and tissue myeloid cells. Retrovirology 12: 37, 2015.

86. Martinez-Picado J, McLaren PJ, Erkizia I, Martin MP, Benet S, Rotger M, Dalmau J, Ouchi D, Wolinsky SM, Penugonda S, et al: Identification of Siglec-1 null individuals infected with HIV-1. Nat Commun 7: 12412, 2016.

87. Akiyama H, Ramirez NP, Gibson G, Kline C, Watkins S, Ambrose $Z$ and Gummuluru S: Interferon-inducible CD169/Siglec1 attenuates anti-HIV-1 effects of alpha interferon. J Virol 91: e00972-e00917, 2017.

88. Yu X, Feizpour A, Ramirez NG, Wu L, Akiyama H, Xu F, Gummuluru S and Reinhard BM: Glycosphingolipid-functionalized nanoparticles recapitulate CD169-dependent HIV-1 uptake and trafficking in dendritic cells. Nat Commun 5: 4136, 2014.

89. Farhood B, Najafi M and Mortezaee K: CD8(+) cytotoxic T lymphocytes in cancer immunotherapy: A review. J Cell Physiol 234: 8509-8521, 2019.

90. Joyce JA and Fearon DT: T cell exclusion, immune privilege, and the tumor microenvironment. Science 348: 74-80, 2015

91. Schnurr M, Scholz C, Rothenfusser S, Galambos P, Dauer M, Röbe J, Endres S and Eigler A: Apoptotic pancreatic tumor cells are superior to cell lysates in promoting cross-priming of cytotoxic T cells and activate NK and gammadelta T cells. Cancer Res 62: 2347-2352, 2002
92. Jenne L, Arrighi JF, Jonuleit H, Saurat JH and Hauser C: Dendritic cells containing apoptotic melanoma cells prime human CD8+ T cells for efficient tumor cell lysis. Cancer Res 60: 4446-4452, 2000.

93. Van Dinther D, Veninga H, Revet M, Hoogterp L, Olesek K, Grabowska J, Borg EGF, Kalay H, van Kooyk Y and den Haan JMM: Comparison of protein and peptide targeting for the development of a CD169-based vaccination strategy against melanoma. Front Immunol 9: 1997, 2018.

94. Asano T, Ohnishi K, Shiota T, Motoshima T, Sugiyama Y, Yatsuda J, Kamba T, Ishizaka K and Komohara Y: CD169-positive sinus macrophages in the lymph nodes determine bladder cancer prognosis. Cancer Sci 109: 1723-1730, 2018.

95. Takeya H, Shiota T, Yagi T, Ohnishi K, Baba Y, Miyasato Y, Kiyozumi Y, Yoshida N, Takeya M, Baba H and Komohara Y: High CD169 expression in lymph node macrophages predicts a favorable clinical course in patients with esophageal cancer. Pathol Int 68: 685-693, 2018

96. Ohnishi K, Yamaguchi M, Erdenebaatar C, Saito F, Tashiro H, Katabuchi H, Takeya M and Komohara Y: Prognostic significance of CD169-positive lymph node sinus macrophages in patients with endometrial carcinoma. Cancer Sci 107: 846-852, 2016.

97. Ohnishi K, Komohara Y, Saito Y, Miyamoto Y, Watanabe M, Baba $\mathrm{H}$ and Takeya M: CD169-positive macrophages in regional lymph nodes are associated with a favorable prognosis in patients with colorectal carcinoma. Cancer Sci 104: 1237-1244, 2013.

98. Saito Y, Ohnishi K, Miyashita A, Nakahara S, Fujiwara Y, Horlad H, Motoshima T, Fukushima S, Jinnin M, Ihn H, et al: Prognostic significance of CD $169^{+}$lymph node sinus macrophages in patients with malignant melanoma. Cancer Immunol Res 3: 1356-1363, 2015 .

99. Marmey B, Boix C, Barbaroux JB, Dieu-Nosjean MC, Diebold J, Audouin J, Fridman WH, Mueller CG and Molina TJ: CD14 and CD169 expression in human lymph nodes and spleen: Specific expansion of $\mathrm{CD} 14^{+} \mathrm{CD} 169^{-}$monocyte-derived cells in diffuse large B-cell lymphomas. Hum Pathol 37: 68-77, 2006.

100. Van Dinther D, Lopez Venegas M, Veninga H, Olesek K, Hoogterp L, Revet M, Ambrosini M, Kalay H, Stöckl J, van Kooyk Y and den Haan JMM: Activation of CD8+ T cell responses after melanoma antigen targeting to CD169+ antigen presenting cells inmice and humans. Cancers (Basel) 11: 183, 2019.

101. Topf MC, Harshyne L, Tuluc M, Mardekian S, Vimawala S, Cognetti DM, Curry JM, Rodeck U and Luginbuhl A: Loss of CD169(+) subcapsular macrophages during metastatic spread of head and neck squamous cell carcinoma. Otolaryngol Head Neck Surg 161: 67-73, 2019.

102. Takeuchi H, Tanaka M, Tanaka A, Tsunemi A and Yamamoto H: Predominance of M2-polarized macrophages in bladder cancer affects angiogenesis, tumor grade and invasiveness. Oncol Lett 11: 3403-3408, 2016.

103. Iftakhar-E-Khuda I, Fair-Mäkelä R, Kukkonen-Macchi A, Elima K, Karikoski M, Rantakari P, Miyasaka M, Salmi M and Jalkanen S: Gene-expression profiling of different arms of lymphatic vasculature identifies candidates for manipulation of cell traffic. Proc Natl Acad Sci USA 113: 10643-10648, 2016.

104. Wang B, Liu H, Dong X, Wu S, Zeng H, Liu Z, Wan D, Dong W, $\mathrm{He}$ W, Chen X, et al: High CD204+ tumor-infiltrating macrophage density predicts a poor prognosis in patients with urothelial cell carcinoma of the bladder. Oncotarget 6: 20204-20214, 2015

105. Li JQ, Yu XJ, Wang YC, Huang LY, Liu CQ, Zheng L, Fang YJ and Xu J: Distinct patterns and prognostic values of tumorinfiltrating macrophages in hepatocellular carcinoma and gastric cancer. J Transl Med 15: 37, 2017.

106. Al Dubayee MS, Alayed H, Almansour R, Alqaoud N, Alnamlah R, Obeid D, Alshahrani A, Zahra MM, Nasr A, Al-Bawab A and Aljada A: Differential expression of human peripheral mononuclear cells phenotype markers in type 2 diabetic patients and type 2 diabetic patients on metformin. Front Endocrinol (Lausanne) 9: 537, 2018.

107. Jing W, Guo X, Wang G, Bi Y, Han L, Zhu Q, Qiu C, Tanaka M and Zhao Y: Breast cancer cells promote CD169(+) macrophage-associated immunosuppression through JAK2-mediated PD-L1 upregulation on macrophages. Int Immunopharmacol 78: 106012,2020

This work is licensed under a Creative Commons Attribution-NonCommercial-NoDerivatives 4.0 International (CC BY-NC-ND 4.0) License. 